\title{
Desafios políticos em tempos de Lei Maria da Penha
}

\author{
Lilia Guimarães Pougy \\ Universidade Federal do Rio de Janeiro (UFRJ)
}

\section{Desafios políticos em tempos de Lei Maria da Penha}

Resumo: Este artigo reúne subsídios para o debate sobre alguns dos desafios da política nacional de enfrentamento da violência contra a mulher na efetivação da cidadania feminina. O percurso adotado no tratamento dos desafios políticos obedecerá às inflexões sobre as principais respostas ao fenômeno da violência de gênero e analisará as tendências presentes no cenário após a Lei Maria da Penha, quais sejam, a "judicialização", a "psicologização" e a "assistencialização" das mulheres, dos homens e das famílias. Na primeira parte do artigo, serão discorridos aspectos do marco conceitual e normativo da política para as mulheres. Na sequência, a inflexão sobre a judicialização e as derivações no que se refere ao debate teórico para, em seguida, finalizar o artigo com as perspectivas atuais da atenção às mulheres nos Centros de Referência.

Palavras-chave: violência de gênero, políticas públicas, Lei Maria da Penha.

\section{Political Challenges in Times of the Maria da Penha Law}

Abstract: This article offers support to the debate about national policies to confront violence against women and strengthen feminine citizenship. The route adopted in treating political challenges will follow the analysis of the principal responses to the phenomena of gender violence and analyze the trends identified since the enactment of the Maria da Penha Law, including increased emphasis on the "courts," "psychology" and "social work." The first part of the article analyzes the conceptual and normative factors of policy concerning women. An analysis is then conducted of "judicialization" and its consequences for the theoretical debate. The article concludes by presenting current perspectives on care for women at Reference Centers.

Key Words: gender violence, public policies, Maria da Penha Law. 


\section{Apresentação}

Esse trabalho é um resultado parcial da pesquisa Violência de gênero em tempos de Lei Maria da $P e n h a^{1}$, que focaliza o estudo da intersetorialidade e da interjurisdicionalidade no enfrentamento à violência de gênero, através do contraste da Política Nacional de Assistência Social (PNAS) e do Plano Nacional de Políticas para as Mulheres (PNPM), em dois planos: a análise das referências legais e o exame das práticas sociais correlatas.

A Lei Maria da Penha (BRASIL, 2006) se apresenta como importante marco na efetivação da política para as mulheres ${ }^{2}$. Transcorridos três anos de sua criação, pretende-se inventariar alguns dos seus impactos no cotidiano dos entes constituintes do Pacto Nacional, em especial dos Centros de Referência ${ }^{3}$, envolvidos com ações de prevenção, proteção, assistência e garantia de direitos, no quadro atual de adensamento da mediação judicial da violência doméstica, por meio da instalação dos Juizados da Violência Doméstica e Familiar contra as Mulheres.

O percurso adotado no tratamento dos desafios políticos obedecerá às inflexões sobre as principais respostas ao fenômeno da violência de gênero e análise das tendências presentes no cenário após a Lei Maria da Penha, quais sejam, a "judicialização", a "psicologização" e a "assistencialização" das mulheres, dos homens e das famílias. As práticas de judicialização se fortaleceram a partir da Lei 9.099/95 (BRASIL, 1995), que dispõe sobre os Juizados Especiais Cíveis e Criminais, destinados aos crimes de menor potencial ofensivo e se consolidam com a Lei 11.340/06 (BRASIL, 2006). Com a criação dos Juizados da Violência Doméstica e Familiar contra a Mulher, outras medidas foram agregadas, fortalecendo ações de assistência à mulher, na forma de apoio, esclarecimento e orientação a respeito dos equipamentos sociais disponíveis; e por fim, ações psicologizantes, na base de apoio clínico - grupal, sobretudo -, que pretendem "tratar", e por vezes até "curar", as sequelas individuais do fenômeno. Cada uma das tendências são corolários das concepções teóricas e políticas sobre a violência de gênero, sua incidência na realidade brasileira e, em particular, na formulação e implementação de políticas sociais, no campo de intervenção interdisciplinar, no qual comparecem assistentes sociais, psicólogos, advogados e pedagogos, entre outras profissões.

\section{Quadro conceitual e marco normativo}

O tema proposto será desenvolvido, com base no quadro teórico que considera as relações de gênero um dos fundamentos da vida social (SAFFIOTI; ALMEIDA, 1995; ALMEIDA, 1998, 2007; POUGY, 2005,
2008). Desta feita, o debate sobre o fenômeno da violência de gênero tem raiz em sua dimensão constituinte, a das relações sociais. Considera-se que o espaço de produção da violência de gênero é "societal" 5 e seu caráter é relacional, ou seja, é um fenômeno social produzido no contexto de densas relações de poder imersas na sociedade contraditória - um tempo e espaço pleno de paradoxos e contradições no qual, "a ideologia do poder mantém o seu controle sobre a consciência popular, pregando com sucesso a eterna validade do sistema de capital estabelecido" (MÉSZÁROS, 2008, p. 130).

De acordo com Almeida (1998, 2007), a violência de gênero é fenômeno social que deve ser deslindado no campo contraditório da sociedade contemporânea, não pode ter seu enfrentamento reduzido ao tratamento dos sujeitos nela implicados, direta ou indiretamente, o que patologizaria comportamentos exacerbados. Antes, deve ser compreendida como uma das expressões das desigualdades sociais que fecundam também diversamente a classe social, o gênero e a etnia. Essa autora discorda da "dualidade conceitual que distingue os processos de vitimação e vitimização" ", uma vez que tem como solo a compreensão de que o sujeito seja exterior às relações sociais.

Essa dualidade assenta-se na premissa de que os sujeitos podem ser constituídos fora das relações sociais fundamentais e de que estas não se materializam nas relações interpessoais. Além disso, supõe [...] que as relações de classes são desvinculadas das demais contradições estruturadoras do real, o que imprime uma visão reducionista à vida social: concepção economicista da vitimação e psicologizante da vitimização (ALMEIDA, 2003, p.100).

Na II Conferência Nacional de Políticas para as Mulheres, realizada em agosto de $2007^{7}$, o conceito de violência contra as mulheres dirige-se para uma concepção teórica totalizadora, inspirada pela definição de violência contra a mulher da Convenção de Belém do Pará ${ }^{8}$, que também iluminou aquela enunciada na Lei Maria da Penha. O capítulo quatro do II Plano Nacional de Políticas para as Mulheres (PNPM) trata do "enfrentamento de todas as formas de violência contra as mulheres", nas quais se verifique "qualquer ação ou conduta, baseada no gênero, que cause morte, dano ou sofrimento físico, sexual ou psicológico à mulher, tanto no âmbito público como no privado" (Convenção de Belém do Pará, Art. 1). Na interpretação constante do documento, o conceito envolve qualquer forma de violação dos direitos humanos das mulheres, seja com vinculação afetiva, seja comunitária ou ainda a violência institucional, praticada por agentes do Estado'. Com efeito, o texto legal também recepciona e detalha di- 
ferentes formas de violência doméstica e familiar no Art.7, nas suas expressões física, psicológica, sexual, patrimonial e moral.

Não obstante, o progressivo ganho no enunciado político sobre os direitos das mulheres, ademais do aumento das áreas - segurança, assistência social, saúde, justiça, cultura, educação, habitação, trabalho - e dos equipamentos da rede de atenção e enfrentamento da violência contra as mulheres, as práticas sociais em curso parecem obscurecer a realização da cidadania feminina, nos moldes de uma concepção teórica totalizadora. A abordagem interdisciplinar visa minimizar a prevalência da orientação disciplinar, por exemplo, a ênfase na orientação jurídica, clínica ou psicossocial, para a pluralidade de disciplinas que comparecem na proposição e atuação cotidiana, o que deve ser emanada de um projeto teórico-político, no qual sejam planejados horizontes de longo, médio e curto prazos, a exemplo da direção da política nacional para as mulheres. Dito em outros termos, construir uma ação integral que focalize as mulheres como sujeitos por inteiro, na qual o foco na situação presente não restrinja, tampouco hierarquize, as perspectivas futuras.

As diversas implicações desse fenômeno complexo de difícil equacionamento não podem ser negligenciadas no campo da formulação política como também no cotidiano dos serviços da rede de atendimento. De acordo com Almeida (2003, p. 99), a negligência quanto à complexidade da violência de gênero coloca em risco "as possibilidades de assistência às vitimas", o que pode reiterar sua vulnerabilidade e risco de vida e de morte, bem como aumentar a distância da condição de sujeito de direitos. É fundamental, nessa linha de raciocínio, "combater a cultura vitimista", dado que seus "corolários são a passividade, a fragilização da luta, a despotencialização dos envolvidos."

A despotencialização dos sujeitos envolvidos nos episódios de violência tem como ponto de partida a ideia de um atendimento "conscientizador" ou habilitador de uma nova postura de homens e mulheres. Com essa marca, os serviços de orientação jurídica dos anos 1980, buscaram responder à politização do tema, na qual o repúdio contra a violação dos direitos das mulheres ainda era modesta na forma de resposta do Estado brasileiro. As campanhas sensibilizadoras para o problema da violência contra a mulher, lideradas pelo feminismo e pelo movimento de mulheres ${ }^{10}$, conseguiram pautar o tema nas agendas políticas dos governos estaduais e no contexto constituinte e participar do jogo democrático, ainda que modestamente. Gregori (1993, p. 14-199), em estudo clássico sobre violência contra a mulher, no qual examinou a "lógica da queixa" com base no contraste entre "a visão feminista" e "as concepções das mulheres que sofrem violência”, aponta para a inconsistência da alteração do quadro de opressão da mulher "apenas no nível da consciência". Não obstante, suas considerações focaram o nível de interação dos sujeitos - homens e mulheres - abstraídos do contexto histórico de produção de modos de ser e fazer o masculino e o feminino. A tese defendida por Almeida (1998, p. 63), diferentemente, sustenta que "o lugar social em que se encontram os sujeitos, suas representações, seus referenciais, seu reconhecimento social são construídos a partir de sua inserção nas relações estruturadoras do ser social."

Debert e Gregori (2008, p.177), em recente estudo em que examinam a distribuição da justiça e a afirmação dos direitos de cidadania em face dos efeitos e limites da reconfiguração do sistema de Justiça Criminal, sublinham o deslocamento político e semântico da defesa da mulher para a defesa da família. Imputam às feministas a ideia de "que existe um tipo particular de violência, baseado nas assimetrias de poder imbricadas em determinadas relações sociais - as marcadas pelo gênero e que não se restringem à violência familiar", isto é, transbordam essa instituição uma vez que nela, como nas demais, existem variadas expressões da violência que organizam o conjunto das relações sociais, das quais destaco as de gênero e de classe. As autoras (2008, p. 166) compreendem gênero com base nas

[...] dinâmicas dessimétricas [...] têm pontos de encontro e semelhança com outras dessimetrias relacionadas com a produção de diferenças tornadas desigualdades. Gênero não é uma dimensão encapsulada, nem pode ser vista como tal, mas ela se intersecciona com outras dimensões recortadas por relações de poder, como classe, raça e idade.

O enunciado considera o gênero com base no cruzamento com outras dimensões de poder. Na perspectiva da totalidade, as relações de gênero são uma categoria que potencializa o entendimento do conjunto das relações sociais, através de interconexão de uma "dupla dimensão categorial", isto é, "categoria histórica-analítica que estuda as relações entre sujeitos sociais sexuados ou gendrados a partir de suas práticas sociais em conexão com os processos macropolíticos que as engendram e que são por elas constituídos" (ALMEIDA, 2007, p. 26). Desse modo, as práticas sociais experimentadas por homens e mulheres não podem ser abstraídas dos processos que as fomentam; os lugares sociais desiguais - de gênero, de classe e étnico-raciais - são constituintes e constituídos nos/pelos processos sociais.

No texto da Lei Maria da Penha, o tipo criminal é a violência doméstica e familiar contra a mulher, o que foi fundamental para a inserção no sistema de Justiça Criminal, buscando coibir e punir os(as) responsáveis pela agressão, mas o fenômeno a ser combatido é a violência de gênero e esse processo 
não se esgota na judicialização, mas também nas ações de proteção, assistência e prevenção. Se as ações relativas aos eixos estruturantes da política e à rede de atendimento são específicas, as escolhas das concepções teóricas e políticas dos projetos são distintivas e dependentes do sucesso para a construção da cidadania.

Debert e Gregori (2008, p.166) observam “o encapsulamento da violência pela criminalidade e o risco concomitante de transformar a defesa das mulheres em defesa da família", já que a distribuição da justiça está marcada pelas relações de poder dos grupos em disputa no jogo democrático, sendo necessário distinguir "entre os significados de processos de violência e daqueles processos que criminalizam abusos." A tensão também examinada por Debert e Oliveira (2007) utiliza um debate da harmonização dos conflitos, tese implícita nas práticas de conciliação e mediação. $\mathrm{O}$ acesso à justiça envolve considerar a ética do certo ou errado, na qual um juizado arbitrará sobre vencedores e perdedores, desconsiderando as causas da contenda. Já a perspectiva da harmonia explorará a ética do "tratamento", sobretudo na forma de trato clínico para superar/restaurar a situação vivida $^{11}$; neste caso, existe acordo e conciliação, no qual todos são vencedores, considerando tão somente as manifestações da discórdia, por meio do consenso. As autoras (2007, p. 175) sublinham que, em ambas as tendências, verifica-se a "hipocrisia da defesa da família."

Com efeito, a família, uma instituição consagrada pela função de colaborar na produção de membros adequados aos destinos hegemônicos de gênero, classe e étnico-racial, parece ser enunciada com base numa concepção distante da pluralidade de arranjos observados no cotidiano, o que pode reiterar o fingimento observado. A família brasileira sofre profundas alterações, não obstante a expectativa do Estado para que seja a grande provedora de cuidados dos seus membros, instituição consagrada nos programas sociais da área da assistência social e nas práticas dos Juizados da Violência Doméstica e Familiar contra a Mulher, com base na própria Constituição Federal, de 1988 (BRASIL, 2004). A incorporação da família no texto legal deve servir à sua proteção, até mesmo para realizar a defesa e guarita dos seus membros. Alves e Barsted (1987, p. 168) em texto clássico sustentam que "o direito sobre a família atualiza as relações de poder ao nível de suas instâncias microssociais, ao nível do cotidiano, das práticas e dos sentimentos", no qual,

[...] a família estruturada pela legislação brasileira não é o reflexo da forma de relacionamento do grupo familiar conforme vivenciada em todas as classes sociais. É antes, a codificação de uma visão de mundo da classe dominante, preocupada com a legitimação, em termos legais, dos laços familiares [...] (ALVES; BARSTED, 1987, p.167).

O crescimento de mulheres chefes de família nos últimos dez anos, de acordo com a Síntese de Indicadores Sociais 2008, do IBGE (2008), foi de nove pontos percentuais e os programas da área da assistência social, uma das áreas previstas na Lei Maria da Penha, estão concentrados na figura da mulher. Isto porque a tendência demograficamente demonstrada encontra na chefe de família a figura da manutenção de vínculos e a administradora dos mínimos distribuídos na forma de bolsa, o que corrobora a tese de Combes e Haicualt (1986, p. 28) a respeito da centralidade da dominação e opressão das mulheres por meio dessa instituição.

\begin{abstract}
A família [...] é o resultado de uma delegação crescente de poder dos capitalistas ao Estado em tal questão. [...] uma intervenção tentacular e multiforme do Estado, [...] mantendo e desenvolvendo um aparelho policial e judicial, normas legislativas, em síntese, tudo o que contribua para fixar as condições sociais da reprodução.
\end{abstract}

Com efeito, as desigualdades de gênero também persistem, em outras áreas: os dados do IBGE dão conta de que as mulheres ocupam menos cargos de chefia do que os homens, não obstante o grupo feminino ter uma média mais alta de anos de estudos, o que as qualificaria para ocupação em cargos de chefia.

Para o contexto de envolvimento do campo da justiça e do direito, por meio do novo tipo criminal, violência doméstica e familiar contra a mulher, e o correspondente adensamento do sistema de Justiça Criminal na resposta do Estado para coibir, punir, assistir e promover direitos, Debert e Gregori (2008) advertem para o retrocesso que as tendências de acesso e distribuição da justiça podem reforçar. Com efeito, ao reiterar o lugar feminino responsável pelas atividades da reprodução social por meio da produção de seres humanos, a mulher é mais uma vez posicionada como a grande responsável pelo cuidado com a família. As autoras observam que o significado dos processos que geram a violência de gênero e os processos que criminalizam abusos não podem ser confundidos. Todavia, se, ainda que distintos, não forem reunidos, o campo da judicialização permanece fraturado. É importante que haja a tentativa de restaurar a cidadania feminina por meio dessa iniciativa, ainda que outras lhe devam ser adicionadas.

A violência de gênero é o resultado da dominação-exploração de mulheres ao longo da história, perpetrado por sujeitos - homens e mulheres - que potencializam a eficácia da ordem vigente na produção massificada de pessoas - homens e mulheres para operarem no nível imediato, contudo, incapaci- 
tadas para estabelecerem os nexos entre os fatos e suas origens macroscópicas e microscópicas. O solo fértil para a violência de gênero são as desigualdades sociais. As condições masculina e feminina são desiguais e o tratamento judicial do tipo criminal não deve ser tolerado e atenuado, como se o seu impacto incidisse sob relações interpessoais que exacerbaram em conflito e pudesse haver uma solução mágica para corrigir desajustes.

Em que pese a redundância, o gênero relacional se exprime através das relações sociais como categorias histórica e analítica por meio do que Kergoat (1996, p. 21) designou visão global do social, dado que "[...] repousa em antagonismos e contradições, bem como em termos materialistas, pois toda relação social tem um fundamento material."

No debate sobre a necessária, conquanto insuficiente, articulação da produção e da reprodução que avalio oportuna para a perspectiva em pauta,

[...] ainda resta raciocinar em termos de relações sociais. [...] e é fácil resvalar entre os campos teóricos (produção, reprodução) e os lugares concretos onde a divisão social do trabalho (entre classes, entre sexos) se opera (a fábrica, a família) ( KERGOAT, 1986, p. 81-82).

O desafio enorme em tempos da consolidação da política de enfrentamento da violência contra a mulher é estimular práticas de atenção que busquem revitalizar a condição cidadã das mulheres em situação de violação de direitos, independentemente dos lugares em que se manifestam a violência e a atenção.

Desfiados esses veios, passo a reunir elementos para uma inflexão do debate teórico sobre as respostas políticas ao fenômeno da violência de gênero.

\section{Respostas em desenvolvimento}

As reações do Estado brasileiro e dos organismos da sociedade em face da violência de gênero têm alargado o campo de afirmação da cidadania feminina e dos direitos humanos ${ }^{12}$. Todavia, em que pese o constrangimento da celebrada expansão nos marcos da sociedade capitalista ${ }^{13}$, a realização da cidadania plena - feminina e masculina - está condicionada ao projeto de sociedade que consiga universalizar o acesso aos direitos, projeto incompatível com o capitalismo.

Nos debates da academia, há recorrência do tratamento da judicialização como relações interpessoais, talvez por se tratarem de histórias de pessoas e destinos de gênero, embora haja a utilização da expressão relações sociais, mas de modo adjetivo. Rifiotis (2004, p. 114) estuda a "judiciarização" das relações sociais que enuncia como a tradução "de um duplo movimento: de um lado a ampliação do acesso ao sistema judiciário e por outro, a desvalorização de outras formas de resolução de conflito." Em instigante ensaio sobre os limites e possibilidades conceituais da violência, o autor equaliza as variadas manifestações no campo dos estudos e práticas, perfilando violência conjugal, violência intrafamiliar e violência de gênero para criticar a "judiciarização" e a "simples repressão", uma vez que, de acordo com o seu entendimento, esta consagra o "privilégio da responsabilização e punição individual, como uma solução biográfica de contradições sistêmicas [...] e uma pedagogia da pena" (RIFIOTIS, 2006, p. 30), o que parece se coadunar com parte das argumentações dos juristas da criminologia critica contrários à penalização. A compreensão de que a "judiciarização" envolve um "conjunto de práticas e valores que interpretam a violência conjugal de modo criminalizante e estigmatizante", na qual se reafirma a dualidade vítima e agressor, tratada por meio de oposição simples, onde um polo vence o outro. Proponho outro exercício, qual seja a aplicação da oposição dialética, o que envolve o movimento da tese, da antítese e da síntese, ponto de partida para novo processo dialético, na qual homens e mulheres poderiam ser transformados após a punição dos atos criminosos. A desinência no plural tenta retirar dos sujeitos envolvidos imediatamente na contenda o fardo de ter apanhado ou ter espancado e, ainda, remeter para os demais sujeitos - operadores de direito e equipes multidisciplinares -, que reanimam e estimulam respostas parciais ao fenômeno de origem social, insisto, a tarefa de entender a relação dos indivíduos na sociedade. Para tanto, a intervenção interdisciplinar é fundamental, na qual as diferentes disciplinas e profissões distintas poderiam reunir subsídios à construção de metodologias inovadoras. O longo excerto extraído de Almeida (2007, p. 35) sustenta a intervenção interdisciplinar, que requer:

a) a capacidade analítica das suas determinações estruturais, dos seus condicionantes conjunturais, das relações intersubjetivas envolvidas e dos mecanismos institucionais disponíveis e/ou mobilizáveis; b) escuta qualificada no sentido de identificar as demandas dos sujeitos envolvidos [...] e favorecer a reconstituição e apropriação crítica de suas próprias experiências [...]; c) [...]itinerário reflexivo-individual e coletivo [...]; d) condenação clara das práticas de violência como ato político de defesa da liberdade, da cidadania e dos direitos humanos, e não como julgamento moral ou expressão de solidariedade vitimista, que tende a construir dicotomicamente os lugares do algoz e da vítima [...].

As delegacias especializadas de atendimento à mulher, de acordo com Rifiotis (2004), atuam como 
"correia de transmissão" entre os serviços de polícia e o campo judiciário, sendo o seu foco a instrução dos processos criminais, ainda que uma função adicional seja funcionar na "mediação social no interior das relações sociais privadas". Essas inferências, sendo o resultado de pesquisas nas delegacias, apresentam um quadro preciso do cotidiano dessas instituições, no qual os casos e conflitos recebem um tratamento extra legal, baseados tão somente no bom, ou mau, senso da/o escrivã/o e delegada/o. A ideia subjacente é a de que o trabalho do policial se operaria exclusivamente no combate ao crime, hierarquizando as demais atividades rotineiras, assistenciais e de manutenção da ordem para o segundo plano (BEATO FILHO, 1999).

A polícia como órgão do judiciário deve cumprir sua função constitucional de enquadramento dos crimes e de instrução dos inquéritos a serem encaminhados para as demais instâncias do sistema. No caso das delegacias especializadas de atendimento à mulher, e de acordo com um padrão verificado por Beato Filho (1999) nas demais distritais, o delegado é quem ocupa a posição de juiz de instrução, ou seja, é quem julga se alguém ingressa ou não no sistema. A resolução de problemas e/ ou as mediação das relações conflituosas, se podem ocorrer por demanda ou exigência dos próprios envolvidos, não podem ser recepcionadas pelo agente do poder público, tampouco carecem de julgamento moralizador ou restaurador de um padrão familiar anacrônico. Nesses casos, às mulheres é imputado o fracasso, seja na manutenção da relação em nível socialmente tolerável, seja da não tentativa de ruptura com a situação de violência ou ainda, na educação da prole.

Os entes do sistema de Justiça Criminal, em especial os Juizados da Violência Doméstica e Familiar contra a Mulher, enfrentam o cotidiano de impotência na resolução dos conflitos imbuídos do dever de aplicar a lei, o que avalio fundamental, dado que medidas de punição e proteção são necessárias. Esse sentimento toma de assalto todas/os as/os profissionais envolvidos com a política, nos diferentes espaços da rede de atendimento. $\mathrm{O}$ fundamento ${ }^{14}$ material da impotência tem origem na compreensão da violência de gênero como fenômeno da ordem da cultura e/ou da família, como se as mesmas não integrassem a sociedade como produto e como processo de densas relações de poder. Quando se estabelece como meta a resolução do problema da mulher, pode- se incorrer numa dupla armadilha: caminhar na contracorrente do empoderamento feminino e patologizar as relações ao estabelecer medidas de medicalização ou tratamento. A mulher protagonista da judicialização tem motivações variadas para a tentativa de ruptura da situação de violência de gênero e não pode ser revitimizada, dessa vez por agentes públicos. A judicialização se apresenta como uma das etapas da sua autopercepção como sujeito de direitos, mas os demais processos conexos devem ser mobilizados.

As intensas conexões nas experiências de desenvolvimento de políticas públicas de gênero foi objeto de análise de Moraes (2006). A hipótese da autora sugere que "o tratamento de conflitos pessoais nas instituições públicas vinculou questões privadas e da dimensão da intimidade" o que permitiu a "introdução do universo impessoal do direito no mundo pessoal e privado" (MORAES, 2006, p.63).

Alves e Barsted (1987) apontam para a intensa articulação deste campo na vida pessoal, em razão de sua função de dominação (repressão) e direção (hegemonia), ademais de entenderem o direito como uma instância mediadora das esferas política e econômica na realização de hegemonia de uma classe social. À exemplo do entendimento de Riffiotis, Moraes (2006, p.63) considera a judicialização um sinal de duplo sentido, "de um lado a ampliação do acesso ao sistema judiciário e por outro, a desvalorização de outras formas de resolução de conflito", sem, contudo, desenvolver as maneiras adicionais de realização da justiça. O conflito a ser dirimido, de fato, transborda de um setor do atendimento, no caso o sistema de Justiça Criminal ou mesmo o conjunto dos setores envolvidos na rede ou da política para as mulheres, tangenciando uma sociedade onde não haja desigualdades sociais e de gênero. O porvir, de acordo com Vásquez (1977), diz respeito à atividade teleológica, uma realidade futura, que precisa ser construída, portanto.

Considero a judicialização fundamental ao projeto de universalizar o acesso à justiça de camadas alienadas dos direitos humanos. Evidentemente que o resultado imediato mais visível é o inchaço das Varas e dos Juizados, do Ministério Público e de todo os entes constituintes do sistema de Justiça Criminal, a começar pela polícia, face mais visível do sistema, nos termos de Beato Filho (1999). A judicialização da violência de gênero, na perspectiva aqui esposada, visa o favorecimento da alteração da correlação de forças 
entre os sujeitos que a vivem, a concretização da legalidade e a realização da justiça.

Atenuar a punição da violência de gênero, nas expressões consagradas nos instrumentos internacional e nacional dos direitos humanos, por meio do reducionismo, da fragmentação e da individualização do fenômeno, é calço com que se opera a minimização da violência e "constituem a face moderna das estratégias de restauração da ordem vigente" (ALMEIDA, 2007, p. 35). A face modernizadora do enfrentamento da violência de gênero, de acordo com Louis (1996, apud ALMEIDA, 2007, p. 33), merece destaque.

[...] A análise em termos de relações individuais, portanto, evoluiu para a consideração da dimensão estrutural sexuada dessas violências, ao passo que os mecanismos que historicamente tiveram por finalidade e/ou por função ocultar, travestir, legitimar essa violência masculina foram analisados. Assim, os argumentos expostos há séculos para desresponsabilizar parcialmente ou totalmente os autores dessas violências ou para justificar parcialmente ou totalmente seus crimes foram denunciados.

Não obstante argumentos dessa natureza, ainda comparecem com força no conjunto dos entes da rede de atendimento, renovando tendências de patologização da violência de gênero como se fosse uma relação anacrônica de pessoas destemperadas. Em muitas situações a mulher acaba sendo revitimizada, considerada fraca, irresponsável, provocadora e resistente às funções e aos papéis sociais destinados ao seu gênero e classe. O grande desafio que se coloca é a instauração de práticas interdisciplinares, nas quais a intervenção seja orgânica ao projeto da sociedade que se deseja, situação possível com base na elaboração e desenvolvimento de um plano teórico-político consistente. As bases estão dadas com a larga experiência no campo do enfrentamento da violência contra a mulher e também previstas no texto da Lei Maria da Penha, especialmente nos Art. 9 e 29, "Da assistência à mulher em situação de violência doméstica" e "Da equipe de atendimento multidisciplinar".

O que se observa nesse curto lapso temporal de instalação e funcionamento dos Juizados ou Varas Especializadas é a mimetização das ações previstas na Norma Técnica dos Centros de Referência. A conceituação dos Centros de Referência é definidora de um espaço de auto assenhoramento da condição da mulher no conjunto das relações sociais.

[...] são espaços de acolhimento/atendimento psicológico, social, orientação e encaminhamento jurídico à mulher em situação de violência, que pro- porcione o atendimento e o acolhimento necessários à superação da situação de violência ocorrida, contribuindo para o fortalecimento da mulher e o resgate da sua cidadania.

[...] devem exercer o papel de articulador das instituições e serviços governamentais e não governamentais que integram a Rede de Atendimento, [...] [...] devem prestar acolhimento permanente às mulheres que necessitem de atendimento, monitorando e acompanhando as ações [...] (BRASIL, 2006, p.15).

Nesse sentido, esse ente da rede de atendimento é concebido como polo de referência da tentativa de ruptura da situação de violência de gênero, dinamizando o acesso aos demais entes e às soluções que consegue vislumbrar, com base em orientação e apoio, o que poderá potencializar o resgate de sua condição cidadã.

De acordo com o texto legal, a equipe multidisciplinar deve "ser integrada por profissionais especializados nas áreas psicossocial, jurídica e de saúde" (BRASIL, 2006, Art. 29 e 60) e compete à equipe de atendimento multidisciplinar,

[...] fornecer subsídios por escrito ao Juiz, ao Ministério Público e à Defensoria Pública, mediante laudos ou verbalmente em audiência, e desenvolver trabalhos de orientação, encaminhamento, prevenção e outras medidas, voltadas para a ofendida, o agressor e os familiares, com especial atenção às crianças e aos adolescentes.

Desse modo, das funções previstas para as equipes multidisciplinares dos juizados e das varas, a primordial é o assessoramento técnico, tendo em vista que as demais funções, necessárias conquanto insuficientes, serão sempre balizadas pelo tempo do processo judicial. A trajetória da mulher na tentativa de ruptura é irregular, ambivalente, e não deve ser restrita ao compasso institucional. Mas os Juizados e Varas, como entes fundamentais da construção da cidadania feminina, deverão estar atentos a esta etapa, quando assim a mulher o considerar.

\section{Conclusão: inventário preliminar}

As políticas públicas enfrentam um enorme desafio: as construções da intersetorialidade e da interjurisdicionalidade, nas quais não existam hierarquias entre setores e jurisdições, mas sim, a concentração de forças na universalização do acesso aos direitos humanos, como forma de contribuir na ampliação dos espaços de direito a ter direitos.

Nessa direção, a política de enfrentamento à violência contra a mulher, no balanço das ações do biênio 2006-2007, previu o ingresso na rede de atendimento dos Centros de Referência de Assistência 
Social (CRAS), dos Centros de Referência Especializado de Assistência Social (CREAS), estruturas existentes no Sistema Único de Assistência Social (SUAS), política pública em construção há mais de 30 anos. Previu, ainda, a inserção dos Centros de Educação e Reabilitação do Agressor, serviço previsto no inciso V do Art. 35, relativos às Disposições Finais da Lei ${ }^{15}$ (BRASIL, 2006). No caso dos CRAS e CREAS, a Secretaria de Política para as Mulheres (SPM) e o Ministério do Desenvolvimento Social e Combate à Fome (MDS) - que abriga a Secretaria Nacional de Assistência Social, responsável pela gestão nacional da política de assistência social - estabeleceram um acordo de cooperação técnica com vistas ao movimento tentacular de expansão da rede de atendimento à mulher. Existem cerca de 5.042 CRAS e 1.054 CREAS e 138 Centros de Referência para as Mulheres (SPM) no Brasil. Capilarizar a rede de serviços é fundamental e esses espaços têm servido para a implantação de políticas públicas. Todavia, o foco da política de assistência é a família e o objeto das políticas para as mulheres é sua proteção. A família é uma instituição indubitavelmente violenta para as mulheres porque está acima de qualquer suspeita e sua preservação se sobrepõe à integridade física, moral e emocional de seus membros. O Pacto Nacional de Política para as Mulheres, concertação intersetorial e interjurisdicional, prevê a capacitação de três mil CRAS e CREAS e 200 mil profissionais das áreas da educação, assistência social, segurança, saúde e justiça. Notícia alvissareira, porém insuficiente para enfrentar a escalada ascendente de demandas experimentada pelos distintos setores.

A sustentabilidade da política precisa combinar quadros técnicos permanentes cujos trabalhadores tenham seus próprios direitos trabalhistas reconhecidos pelo Estado federativo, o que requer também o envolvimento orgânico e contínuo dos municípios, dos estados, do Distrito Federal. É fundamental resistir aos cenários adversos de transferência aos organismos da sociedade civil do que é responsabilidade do poder público: formular, implantar e avaliar políticas sociais instrumentalizadoras de direitos sociais; universalizar o acesso à população e garantir a sustentabilidade da ação.

Nesse cenário, uma experiência singular merece ser estudada: trata-se do consórcio entre o Tribunal de Justiça e a Secretaria Municipal de Assistência Social, ambos do estado do Rio de Janeiro, para a instalação do Centro de Referência Especializado da Assistência Social (CREAS Simone de Beauvoir) nas dependências do I Juizado da Violência Doméstica e Familiar contra a Mulher. Essa experiência pioneira, assim como outras em estudo por meio do Observatório da Lei Maria da Penha ${ }^{16}$, certamente será capaz de estabelecer metas orgânicas à direção teórica e política do projeto de sociedade, sem prescindir da perspectiva da totalidade.

As ações em curso são alvissareiras e merecedoras da consolidação do amparo legal propiciado em 2006. É fundamental defender suas premissas essenciais - coibir, punir, proteger, assistir e previnir para que o campo da cidadania e dos direitos humanos não seja violado.

\section{Referências}

II PNPM - PLANO NACIONAL DE POLÍTICAS PARA AS MULHERES. Secretaria Especial de Políticas para as Mulheres - Presidência da República, 2008. Disponível em: $\leq$ http://200.130.7.5/spmu/docs/Livro_II_PNPM_ completo09.09.2009.pdf $>$. Acesso em: set. 2009.

ALMEIDA, S. S. Femicídio: algemas (in)visíveis do público privado. Rio de Janeiro: Revinter, 1998.

$\mathrm{O}$ atendimento multidisciplinar às vítimas. In: III SEMINÁRIO CONSTRUÇÃO DA CIDADANIA: A PRÁTICA EM DEBATE, do NAVCV, SEDH da Secretaria de Estado de Desenvolvimento Social (Sedese). Belo Horizonte, 2003.

Essa violência mal-dita. In: (Org.). Violência de gênero e políticas públicas. Rio de Janeiro: Editora UFRJ, 2007. p. 23-41.

ALVES, B. M.; BARSTED, L. L. Permanência ou mudança: a legislação sobre família no Brasil. In: RIBEIRO, I. Família e valores. São Paulo: Loyola, 1987. p.165-187.

BARSTED, L. L. Em busca do tempo perdido: mulher e políticas públicas no Brasil 1983-1993. Revista Estudos Feministas, Rio de Janeiro, CIEC/ECO/UFRJ, v. 2, número especial, p. 38-54, 1994.

BEATO FILHO, C. C. Políticas de segurança e a questão policial. São Paulo em Perspectiva, São Paulo / Fundação SEADE, v. 13, n. 4, p. 20-50, 1999.

BRASIL. Constituição da República Federativa do Brasil. São Paulo: Atlas, 2004.

Presidência da República. Lei n. 9.099, de 26 de setembro de 1995. Dispõe sobre os Juizados Especiais Cíveis e Criminais e dá outras providências. Disponível em: <http://www.planalto.gov.br/ccivil/LEIS/L9099.htm>. Acesso em: 20 set. 2009.

Lei n.11.340, de 7 de agosto de 2006. Cria mecanismos para coibir a violência doméstica e familiar contra a mulher, nos termos do $\S 80$ do art. 226 da Constituição Federal ... e dá outras providências. 
Disponível em: <http://www.planalto.gov.br/CCIVIL/ _Ato2004-2006/2006/Lei/L11340.htm>.Acesso em: 14 set. 2009.

COMBES, D.; HAICUALT, M. Produção e reprodução. Relações sociais de sexos e de classes. In: KARTCHEVSKY, A. (Org.). O sexo do trabalho. Rio de Janeiro: Paz e Terra, 1986. p. 23-44.

DEBERT, G. G; GREGORI, M. F. Violência de gênero: novas propostas, velhos dilemas. Revista Brasileira de Ciências Sociais, v. 23, n, 66, p. 165-185, fev. 2008.

; OLIVEIRA, M. B. de. Os modelos conciliatórios de solução de conflitos e a 'violência doméstica'. Cadernos Pagu, São Paulo, v. 29, p. 305-337, jul-dez, 2007.

GONÇALVES, H. S.; BRANDÃO, E. P. (Org.). Psicologia Jurídica no Brasil. Rio de Janeiro: NAU Ed., 2004.

GREGORI, M. F. Cenas e queixas: um estudo sobre mulheres, relações violentas e a prática feminista. Rio de Janeiro: Paz e Terra, 1993

IBGE - Instituto Brasileiro de Geografia e Estatística. Síntese dos Indicadores Sociais: uma análise das condições de vida da população brasileira, 2008. Disponível em: <http:/ /www.ibge.gov.br/home/>. Acesso em: 12 jun. 2009.

KERGOAT, D. Em defesa de uma sociologia das relações sociais. In: KARTCHEVSKY-BULPORT et. al. O sexo do trabalho. Rio de Janeiro: Paz e Terra, 1986. p. 79-93.

MÉSZÁROS, I. Filosofia, ideologia e Ciência Social: ensaios de negação e afirmação. São Paulo: Ed. Ensaio, 1993.

A desigualdade social crescente, as classes sociais e as formas de organização social In: MENEGAT, M.; BEHRING, E.; FONTES, V. Dilemas da humanidade: Diálogos entre civilizações. Rio de Janeiro: Contraponto, 2008. p.129-165.

MORAES, A. F. Universal e local nas expressões da violência conjugal. Revista de Ciências Sociais, Fortaleza, v. 37, p. 60-78, 2006.

PINTO, C. R. J. Mulher e política no Brasil: os impasses do feminismo, enquanto movimento social, face às regras do jogo da democracia representativa. Revista Estudos feministas, Rio de Janeiro, CIEC/ECO/UFRJ, v. 2, n. 2 p. 256-270, 1994.

POUGY, L. G. Violência de gênero e política de assistência social: As necessidades sociais de mulheres em situação de violência. In: II JORNADA INTERNACIONAL DE POLÍTICAS PÚBLICAS. Anais... São Luiz, Maranhão, 2005.
Respostas do Estado Brasileiro à violação dos direitos humanos das mulheres: homens Autores de violência. In: SEMINÁRIO INTERNACIONALFAZENDO GÊNERO 8: CORPO, VIOLÊNCIA E PODER, 2008. Florianópolis: Editora Mulheres, 2008.

RIFIOTIS, T. As delegacias especiais de proteção à mulher no Brasil e a judiciarização dos conflitos conjugais. Revista Sociedade e Estado. Brasília, v.19, n.1, p. 90-115, jan./jun. 2004.

Alice do outro lado do espelho: revisitando as matrizes das violências e dos conflitos sociais. Revista de Ciências Sociais, Universidade Federal do Ceará v. 37, n. 2,p. 27-33, 2006.

SAFFIOTI, H. I. B. Movimentos Sociais: a face feminina. In: CARVALHO, N. V. de (Org.). A condição feminina. São Paulo:Vértice, 1988. p. 29-55.

.; ALMEIDA, S. S. Cidade Maravilhosa: a outra face. In:______ (Org.). Violência de gênero: poder e impotência. Rio de Janeiro: Revinter, 1995. p. 29-55.

SCHUMAHER, M. A.; VARGAS, E. Lugar no governo: álibi ou conquista? Revista Estudos Feministas, Rio de Janeiro, CIEC/ECO/UFRJ , v. 1, n. 2, p. 348-364, 1993.

SOARES, V. Movimento Feminista: paradigmas e desafios. Revista Estudos feministas, Rio de Janeiro, CIEC/ECO/ UFRJ, v. 2, número especial ,p. 11-24, 1994.

VÁZQUEZ, A. S. Praxis e violência In: Filosofia da praxis. Rio de Janeiro: Paz e Terra, 1977, p. 55-115.

\section{Notas}

1 Trata-se de pesquisa realizada na Linha de pesquisa Estado, Sociedade e Direitos humanos, da Área de Cultura, Cidadania e Serviço Social do Programa de Pós-Graduação da Escola de Serviço Social daUFRJ. O projeto de pesquisa foi aprovado no Edital Humanidade da FAPERJ e conta com estudantes de graduação e pós-graduação.

2 A importância da Lei Maria da Penha na restauração da cidadania feminina pode ser sintetizada pelo enquadramento legal da tese da violência de gênero como violação dos direitos humanos, compromisso firmado pelo Estado brasileiro em instrumentos internacionais, dos quais destaco os dois mencionados no texto da Lei 11.340 (BRASIL, 2006).

3 OCentro de Referência para as mulheres é objeto de estudo e intervenção há cinco anos, quando a SPM/PR e a UFRJ firmaram convênio para o desenvolvimento de um projeto piloto na Vila do João, no Bairro da Maré. Desde então assumi a atividade de supervisão e formação da equipe técnica do 
Centro de Referência de Mulheres da Maré Carminha Rosa (CRMM-CR). No ano de 2009, assumi também a supervisão de outra equipe multiprofissional, a do Centro Integrado de Atendimento à Mulher(CIAM) Márcia Lyra, tambémno Rio de Janeiro.

4 No escopo desse artigo não será possível enunciar os conceitos de todas as tendências, o que exigiria outra lógica de exposição. Preocupa-me o impacto das escolhas teóricas nas ações práticas verificadas. Pretende-se que os conteúdos das tendências estejam presentes na análise, o que poderá permitirinferências iniciais.

5 Utiliza-se a expressão com o significadoemprestado por Suely Souza de Almeida para contrapor a análise dualista que opera por meio da oposição simples do binômio relações interpessoais e macroestruturais.

6 ParaAlmeida(2003,p. 100), a vitimação diz respeitoà violência estrutural e a vitimização à violência interpessoal.

7 Informações sobre a II Conferência Nacional de Políticas para as Mulheres estão disponíveis em: <http:// tesseract.sites.uol.com.br/conferencia.htm>.

8 Informações sobre a Convenção Belém do Pará estão disponíveis em <http://www.cidh.oas.org/Basicos/ Portugues/m.Belem.do.Para.htm>.

9 Tal definição é, portanto, bastante abrangente e abarca diferentes formas de violência, tais como: "a) a violência doméstica ou em qualquer outra relação interpessoal, em que o agressor conviva ou tenha convivido no mesmo domicílio que a mulher; b) a violência ocorrida na comunidade e que seja perpetrada por qualquer pessoa, compreendendo, entre outros, violação, abuso sexual, tortura, tráfico de mulheres, prostituição forçada, sequestro e assédio sexual; c) a violência perpetrada ou tolerada pelo Estado ou seus agentes, onde quer que ocorra (violência institucional)" (II PNPM, 2008,p. 91).

10 Considero importante o detalhamento do movimento feminista explorado por Soares (1994), Pinto (1994) e Saffioti (1988). A respeito do processo de conquistas políticas e seus impasses, Barsted (1994)e Schumahere Vargas (1993).

11 A psicologiajurídica, um ramo da psicologiaem crescimento, tem em gênese numa demanda do campo do Direito, conquanto "busque o seu motor próprio" (GONÇALVES; BRANDÃO, 2004,p. 7).

12 Mészáros (1993, p. 164) trata da rejeição radical de Marx à ideia da "ilusão jurídica", que considera a esfera dos direitos como independente e auto-regulada. Esse autor, adverte, todavia com a preocupação de Marx para com as "condições de liberdade pessoal, entendida como um controle significativo das relações interindividuais pelos próprios indivíduos, e totalmente em oposição às condições determinadas de existência que escapam à sua vontade."

13 Do mesmo autor, a ideia da necessária postura de uma reavaliação constante do propalado crescimento, não com base numa polarização estéril, mas se este processo "deixaria intactas as iniquidades monstruosas do nosso mundo social, ou que as tornaria piores do que nunca" (MÉSZÁROS, 2008, p. 141).

14 Trata-se de fundamento material e simbólico, captado não só por meio das atividades de pesquisa e de supervisão de equipes técnicas como também pelas atividades de ensino por meio da escuta de pós-graduandas do PPGSS/UFRJ, alunas da disciplina "Violência de gênero e políticas públicas", oferecida por mim no primeiro semestre de 2009.

15 Sobre a interface entre as duas políticas nacionais ver Pougy (2005; 2008). Nesteúltimo trabalho tambéméiniciadoodebate sobre os autores da violência de gênero.

16 Trata-se de projeto da SPM-PR que visa monitorar as experiências de instalação dos Juizados e Varas de que trata a Lei Maria da Penha.

\section{Lilia Guimarães Pougy}

liliapougy@cfch.ufrj.br

Doutorado em Ciências Sociais pela Pontifícia Universidade Católica de São Paulo (PUC-SP)

Professora da Escola de Serviço Social da Universidade Federal do Rio de Janeiro (UFRJ) e do Programa de Pós-Graduação em Serviço Social (PGSS/ UFRJ)

\section{UFRJ - Escola de Serviço Social}

Av. Pasteur, 250

Praia Vermelha

Rio de Janeiro - Rio de Janeiro

CEP: 22290-240 